\title{
Prediction of Mechanical Behaviour of a Bulk Epoxy Adhesive in a Marine Environment
}

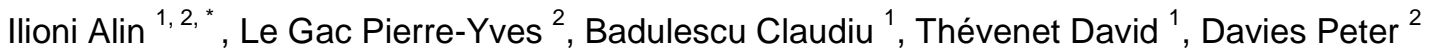 \\ ${ }^{1}$ ENSTA Bretagne, Brest, France \\ ${ }^{2}$ Marine Structures Laboratory, IFREMER, Plouzané, France \\ * Corresponding author : Alin llioni, email address : alin.ilioni@ensta-bretagne.org
}

\begin{abstract}
:
This article describes an approach to predict the behaviour of an epoxy adhesive in bulk form in a marine environment. First, the material, the experimental conditions and the predictive framework are described. Then the experimental results are presented, which indicate that the effects on yield stress of either a uniform water profile or elevated testing temperature can be shown to be equivalent when plotted versus T-Tg. Moreover, a discussion of these results shows how they can be used to predict changes in the mechanical properties of the adhesive. Prediction results for yield stress are in good agreement when they are compared with experimental results for the case of a water profile gradient, in order to evaluate the relevance and limitations of the model.
\end{abstract}

Keywords : Epoxide, water ageing, glass transition temperature, mechanical properties of adhesives, plasticisation 
Structural adhesives have a long history in marine applications, playing a key role in the assembly of pleasure boats and racing craft [1]. The interactions between water and polymers have been studied by many authors, and effects are usually classified as either reversible (plasticization [2], swelling [3]) or irreversible (hydrolysis [4], oxidation). The influence of water on epoxy resins has received particular attention. Zhou \& Lucas described how water bonds with epoxy resins [5], and how this reduces the glass transition temperature [6]. Various studies have shown that significant amounts of water can enter epoxies. For those with amine hardener water content is usually less than $5 \%$. Much higher water content can be observed when the polarity of the polymer increases or when fillers are used. Epoxy based adhesive formulations are more complex, often containing small amounts of fillers and other additives to assist bonding operations. For some epoxy adhesives and exposure conditions the weight gain plots show Fickian behaviour, e.g. [7], in others more complex behaviour is observed. For example, De Nève and Shanahan showed an initial Fickian response followed by a second increase in weight for an epoxy adhesive [8], while Mubashar et al. [9] proposed a dual Fickian model for water ingress into a rubber toughened $120^{\circ} \mathrm{C}$ cure one-part epoxy system.

This water can be quite detrimental to both adhesive properties and their assembled joints, and environmental effects are often cited as one of the main reasons for not using adhesive 
assembly more extensively [10]. For example, Bordes et al. [11] showed drops in adhesive tensile modulus and strength after saturation of up to $50 \%$ of initial unaged values.

In many cases, complete restoration of property losses has been noted after drying e.g. [12], suggesting that adhesive plasticization is the dominant mechanism.

In assembled joints the adhesive/substrate interfaces must also be considered. For example, Zanni-Deffarges \& Shanahan described diffusion of water in adhesives and bonded joints [13]. They found considerably higher diffusion coefficients for the bonded joint, and suggested that capillary diffusion exacerbates water ingress but when focusing on water diffusion in bulk specimens, these considerations can be neglected. Brewis et al. [12] found a linear relationship between joint strength and the water content of metal/epoxy joints but a strong dependency on the aluminium surface preparation, with strength either decreasing or increasing as water content increased. This is not the subject here but it is interesting to note that some authors have suggested that the presence of a critical amount of water at the interface leads to interface failure [14]. A reliable diffusion model is essential to predict the local water concentration. Finally, it should be noted that residual stresses may also have a significant influence on the environmental degradation of adhesive assemblies [15]

There are several useful reviews available concerning moisture effects on adhesive joints; Bowditch presented an overview of the influence of water on durability [16] and Comyn and colleagues have provided detailed reviews of environmental effects [17-19].

This brief overview shows that there are a number of relevant test results in the published literature, and there is also considerable practical experience of the long-term reliability of adhesives in water. However, it is also clear that there is a range of behaviours which depend on adhesive formulation and environmental conditions, and there are few predictive tools available to the designer looking to develop bonded assemblies in new marine applications, such as renewable marine energy structures. There are some exceptions, in particular, the work of Crocombe et al. [20-22], who have developed an overall methodology and also specific approaches based on both damage mechanics [23] and cohesive zone models [24] to account for the influence of moisture in a coupled approach.

Bordes et al. [11] also describe a partially coupled approach to predict long term behaviour during immersion, while other recent work includes that of Arnaud et al. [25], who applied a Mahnken-Schlimmer model [26] with parameters identified on unaged and aged Arcan specimens. Leger et al. [27] have also studied coupling effects; they examined temperature/humidity equivalence in a highly filled adhesive and modelled the influence on mechanical behaviour. Moreover, Viana et al presented a review on the temperature and moisture degradation of adhesive joints [28] and correlated the glass transition temperature of a bulk epoxy adhesive with the water uptake to determine the evolution of its properties as a function of environmental temperature and moisture [29].

The aim of the present paper is to focus on how water ingress in a two-part epoxy adhesive, widely used in marine applications, affects its mechanical behaviour, in order to provide a physically based relationship for subsequent predictive modelling. First, results from a wet aging study are presented. Samples have then been characterized in tension; a first set was tested after conditioning to saturation for different humidity conditions, to produce uniform 
water profiles through the sample thickness; a second set was tested at different temperatures. A semi-coupled model is then applied, to predict the water profiles in immersed samples and predict their tensile behaviour. Finally, predictions of stress-strain plots are compared to test results from a third set of tensile samples immersed for different times.

\section{Material and methods}

\subsection{Material}

Samples studied here were obtained using thin bulk samples made from the epoxy based Huntsman $^{\mathrm{TM}}$ (Europe, B-Everberg) adhesive Araldite $420 \mathrm{~A} / \mathrm{B}$. This is an epoxy based with a Bisphenol A diglycidyl ether prepolymer and a diamine hardener mixed in stoichiometric conditions. Table 1 summarizes initial properties of the bulk adhesive.

\begin{tabular}{cc}
\hline Property & Value \\
\hline Density & $1075 \mathrm{~g} / \mathrm{cm}^{3}$ \\
Inorganic filler content & $4 \pm 1 \%$ \\
$\mathrm{Tg}$ & $66^{\circ} \mathrm{C} \pm 2^{\circ} \mathrm{C}$ \\
Young's Modulus & $1850 \pm 80 \mathrm{MPa}$ \\
Yield Stress & $36 \pm 1 \mathrm{MPa}$
\end{tabular}

Table 1: Main characteristics of the Araldite 420 studied here

\subsection{Samples preparation}

The samples used for this study were obtained from a sheet of adhesive made by mixing 100 parts by weight of the resin A and 40 parts by weight of the hardener B using a Speedmixer at $2500 \mathrm{rpm}$ for 5 minutes. The mixture was compressed between two aluminium plates and the final thickness was controlled using $1 \mathrm{~mm}$ thick spacers. Then the polymer was cured for $1 \mathrm{~h} 10$ at $115^{\circ} \mathrm{C}$. After curing, sheets were removed from the mould and thermally post treated for 1 hour at $80^{\circ} \mathrm{C}$ (i.e. above $\mathrm{Tg}$ ) in order to remove any residual stresses. Samples were then cut out from the sheets using a water jet cutting system.

\section{$2.3 \quad$ Ageing}

Two kinds of ageing were considered here. The first is immersion in continuously renewed natural sea water taken directly from the Brest estuary, more details about Ifremer ageing tanks are available in [30]. The second is a humid ageing at three humidity level $(33,50$ and 75\%) carried out in a Memmert ${ }^{\mathrm{TM}}$ conditioning chamber, type HP110. All ageing was performed at $40 \pm 1^{\circ} \mathrm{C}$ and all samples were dried prior to ageing at $40^{\circ} \mathrm{C}$ in a desiccator until mass stabilization. 


\subsection{Water absorption}

The water diffusion was determined from the weight change of square samples $\left(30 \times 30 \mathrm{~mm}^{2}\right)$. Mass gain was followed by periodic weighing on a Sartorius ${ }^{\mathrm{TM}}$ LA $310 \mathrm{~S}$ balance (precision 0.1 $\mathrm{mg}$ ). Samples were removed from the ageing containers and wiped with paper towels before weighing to dry the surfaces, three samples were tested per condition. The change in water content in each sample $\left(\mathrm{M}_{\mathrm{t}}\right)$ with time is defined with respect to the initial mass of the sample $\left(m_{0}\right)$ using Eq.1, where $\mathrm{m}(\mathrm{t})$ is the mass of a sample at a time $t$ and $\mathrm{m}_{0}$ the initial mass.

$$
M_{t}=\frac{\mathrm{m}(\mathrm{t})-m_{0}}{m_{0}} \times 100
$$

Given the dimensions of the samples, the water diffusion was considered unidirectional. The diffusion coefficient is determined on the initial linear part of the sorption curve, $\frac{M_{t}}{M_{\infty}} \leq 0.5$, $M_{\infty}$ being the mass at complete saturation. Its value is calculated using Fick's 1D law (Eq.2):

$$
D=\frac{\pi}{16} \frac{e^{2}}{t} \times\left(\frac{M_{t}}{M_{\infty}}\right)^{2}
$$

where, $\mathrm{e}$ is the sample thickness in $\mathrm{mm}$ and $t$ is the immersion time in $\mathrm{s}$.

\subsection{Glass transition temperature ( $\mathrm{Tg})$ measurements}

Tg was measured using DSC analysis. The experimental device used for this measurement is a Q200 machine from TA Instruments ${ }^{\mathrm{TM}}$, with a temperature scan between $0^{\circ} \mathrm{C}$ and $100^{\circ} \mathrm{C}$ at a heating rate of $10^{\circ} \mathrm{C} / \mathrm{min}$.

\subsection{Tensile tests}

Tensile tests were performed using at least three dog-bone samples per condition (type 3 in ISO 37 [31]) and an Instron ${ }^{\mathrm{TM}}$ machine with a cross head speed of $0.5 \mathrm{~mm} / \mathrm{min}$. The load was measured using a $500 \mathrm{~N}$ load cell and the strain using a digital image correlation system (DIC).

If not specified, the testing temperature was $21^{\circ} \mathrm{C}$. When samples were tested at higher temperature the samples were held for 20 minutes in the thermal chamber, at the testing temperature, to homogenise the temperature in the thickness of the sample before testing.

Young's modulus is defined as the slope between 0 and $2 \%$ strain. An average and a standard deviation are then calculated using all the tested samples for each condition. The yield stress is considered to be the point where the first derivative of the stress-strain curve changes by more than $5 \%$ of the initial value. Poisson's coefficient is defined as the ratio between the average transverse and longitudinal strains measured by DIC.

\subsection{Modelling of mechanical behavior}

The mechanical model used here to predict the changes in mechanical properties with water conditioning is a simplified version of a more complete viscoelastic-viscoplastic model developed to describe the mechanical behaviour of the adhesive in a bonded joint. The total 
strain $\left(\varepsilon_{t o t}\right)$ is supposed to be the sum of the elastic strain $\left(\varepsilon_{e l}\right)$, the viscoelastic strain $\left(\varepsilon_{v e}\right)$ and the viscoplastic strain $\left(\varepsilon_{v p}\right)$, as shown in Eq.3.

$$
\varepsilon_{t o t}=\varepsilon_{e l}+\varepsilon_{v e}+\varepsilon_{v p}
$$

The viscoelastic part $\left(\varepsilon_{v e}\right)$ is describe using a modified version of the viscoelastic spectral model developed by Badulescu et al. [32] and the parameters were identified using the presented method. The viscoplastic strain $\left(\varepsilon_{v p}\right)$ is based on an approach developed by Cognard et al. [33]. In the current version, it was used in an associated model where both the yield and flow functions are defined using the same function which has a linear dependency on the hydrostatic pressure.

The viscoelastic parameters and the hardening parameters were identified using initial state behaviour (no ageing) and were considered here not to be dependent on environmental conditions. The parameters used to model the evolution of the mechanical properties of the tensile behaviour as a function of water quantity are the Young's modulus, Poisson's ratio and the yield stress.

The mechanical model has been implemented in Abaqus ${ }^{\mathrm{TM}}$ software. In parallel a diffusion model was developed using the equivalence between the water diffusion and the heat transfer (Eq.4):

$$
D=\frac{\lambda}{\rho C}
$$

where $\mathrm{D}$ is the diffusion coefficient in the immersed condition, $\rho$ the density of the material, $C$ the heat capacity and, $\lambda$ the thermal conductivity. Using this model, it is possible to establish the water profile in the thickness of a sample that was immersed in water for a defined period. For this approach, the diffusion was supposed to be unidirectional and the quantity of water diffused through the edges of the sample was considered negligible.

The Finite elements (FE) mesh, more precisely, the number of elements in the thickness of the specimen (Figure 1a) is very important in order to obtain a good prediction of the water diffusion at the beginning of the process. Therefore, a convergence analysis has been performed. The results are shown in Figure 1b. It can be seen that 100 elements in the thickness of the sample are sufficient to obtain a good prediction of the mass change of the sample due to water absorption. 


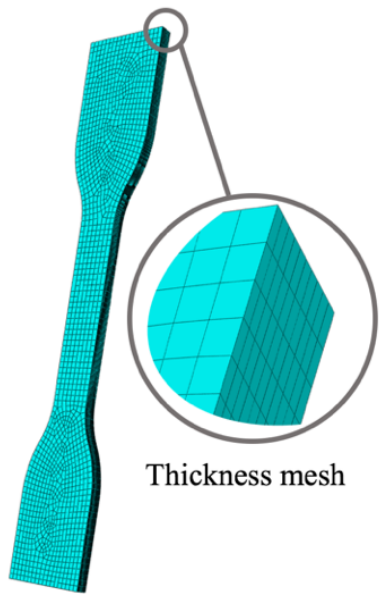

a)

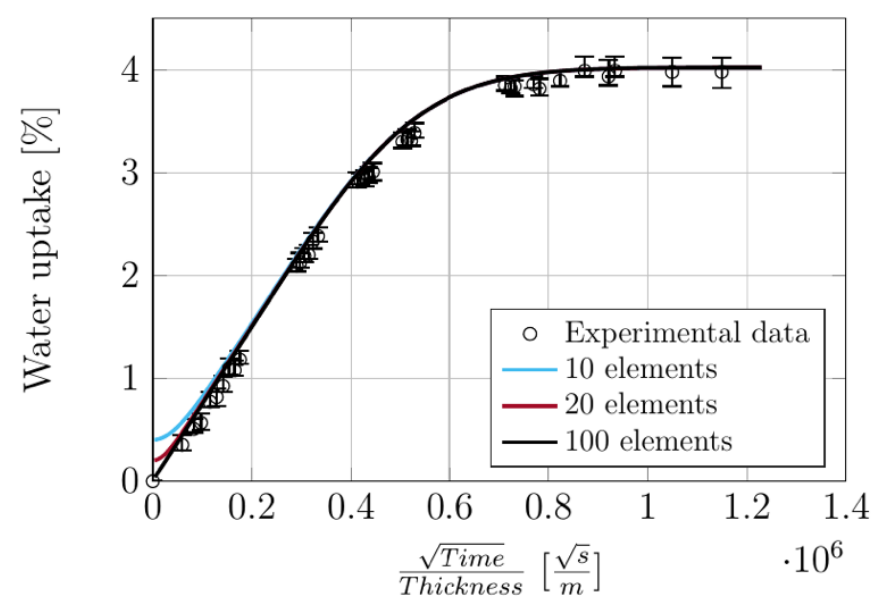

b)

Figure 1: FE model used for used for mechanical behaviour prediction (a), convergence study for water uptake prediction (b)

This diffusion model enables the water profiles through the thickness direction to be established. The changes in the mechanical properties are then related to the water content and integrated at each point of the specimen through the FE mesh.

\section{Results}

This section is devoted to the presentation of experimental results. First, we will focus on water absorption and then on the consequences of the presence of water on both tensile behaviour and Tg changes.

\subsection{Water absorption}

The mass variation measured during exposure of the polymer to a wet environment at $40^{\circ} \mathrm{C}$ is plotted in Figure 2. For each of the conditions considered herein, i.e. a relative humidity of $33 \%, 50 \%$ and $75 \%$ and immersion in sea water, Fickian behaviour is observed, with increasing weight gain during the first stage of ageing and then the appearance of a saturation plateau. Based on these results it is possible to consider two main characteristics for water diffusion: the water diffusivity and the amount of absorbed water.

The water diffusion coefficient is equal to $1.15 \times 10^{-12} \mathrm{~m}^{2} \cdot \mathrm{s}^{-1}$ at $40^{\circ} \mathrm{C}$ and independent of the relative humidity as shown in Figure $3 a$. This value is in accordance with existing results in the literature for epoxy material with an amine hardener [3][34].

The water uptake in the epoxy adhesive at saturation when immersed in sea water at $40^{\circ} \mathrm{C}$ is $4 \%$ by mass, this amount of water is also similar to previous results obtained on epoxy with amine hardener; the presence of a polar group such as amine leads to this high-water absorption. Moreover, as expected, the amount of absorbed water at saturation depends on the water activity in the surrounding environment. The higher the water activity the higher the water content at saturation in the polymer as shown in Figure 3b. However, it also appears that water content at saturation is not directly proportional to the partial pressure of water 
indicating that Henry's law is not verified here. The water content in the epoxy adhesive has been described based on an existing relationship (Eq.5) developed elsewhere [35][36]:

$$
W_{H_{2} 0}=H \times a+N \times a^{m}
$$

where $W_{\mathrm{H}_{2} 0}$ is the water content in the polymer in \%, $a$ is the water activity in the surrounding environment and $H, N$ and $m$ are parameters identified experimentally.

This behaviour is usually explained by a clustering phenomenon where the water can form microscopic droplets of water [37][38]. This will not be considered in detail in this study.

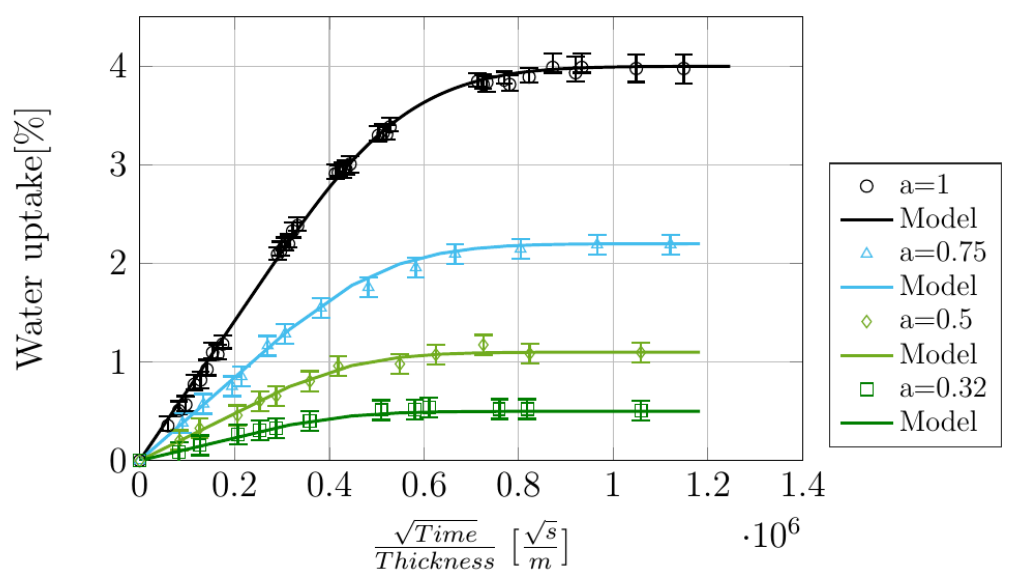

Figure 2: Water absorption in the polymer for ageing conditions considered here (symbols are experimental data and lines are modelling with Fickian behaviour)
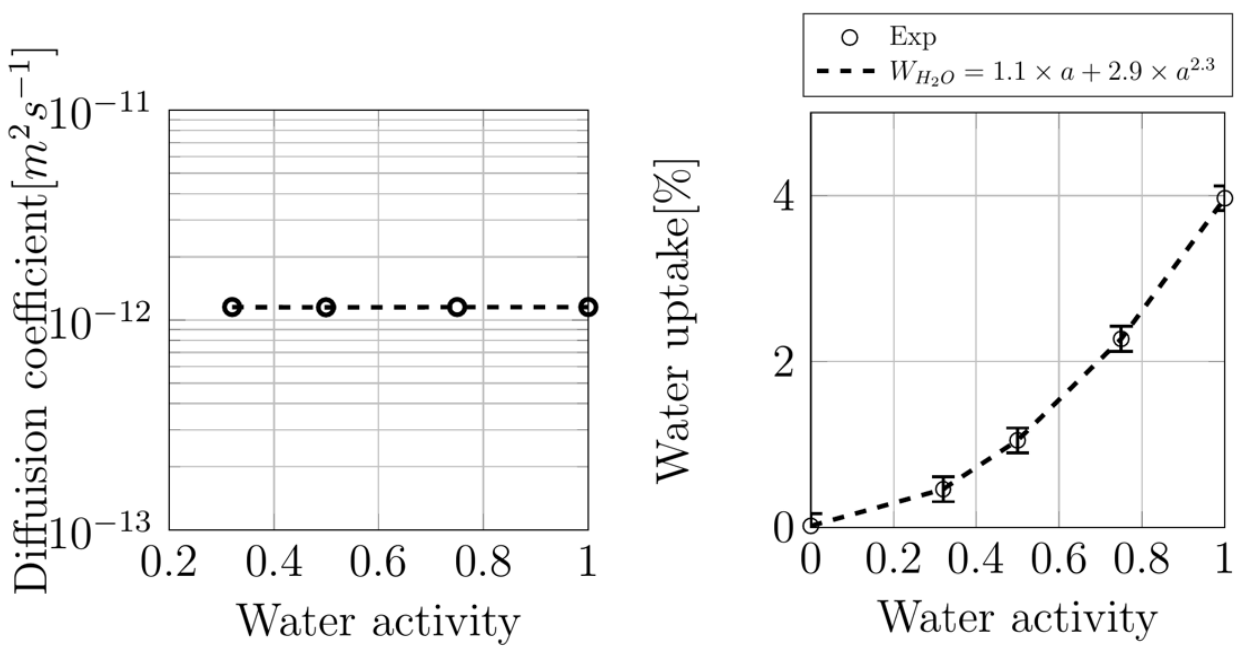

Figure 3: Influence of the water activity in the environment on water diffusion coefficient (a) and water content at saturation in the epoxy (b)

\subsection{Tensile behavior changes with water content}

This section is focused on the effect of the presence of water in the polymer on its mechanical properties. It is worth nothing that all the results presented in this section were obtained on fully saturated samples but with different amounts of water, meaning that there is no water profile through the specimen thickness. Tensile behaviour for several water contents is 
plotted in Figure 4. The presence of water leads to large change in the mechanical behaviour of this epoxy with a large decrease in yield stress, modulus and an increase in strain at break. All these changes in properties are plotted in Figure 5 together with the Poisson's ratio.

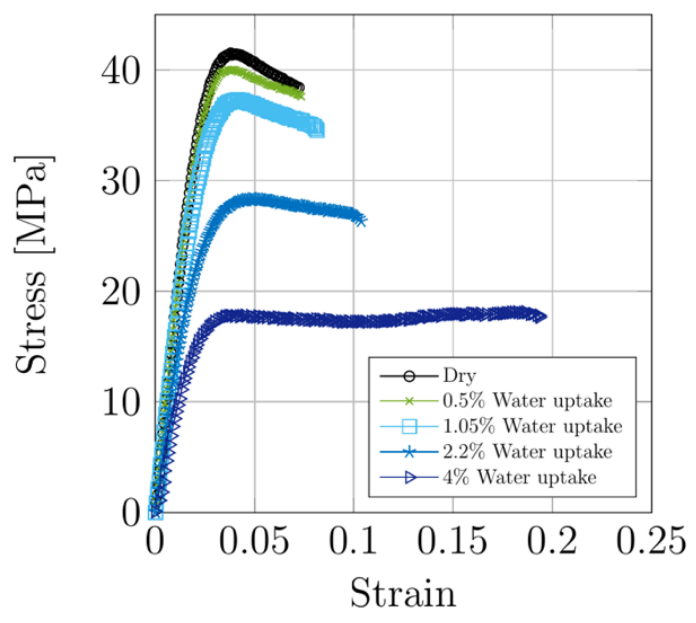

Figure 4: Tensile behaviour as a function of water content at saturation (i.e. without any water profile gradient through the thickness)

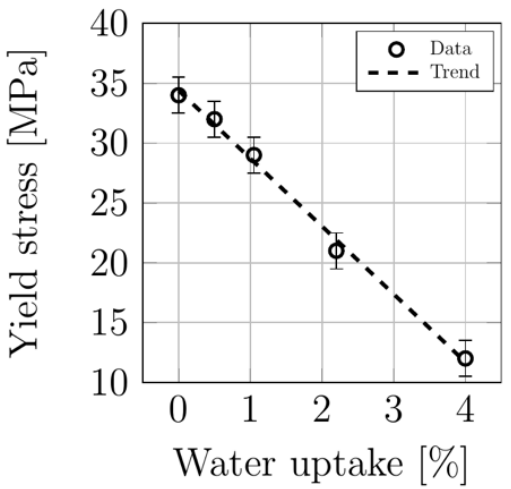

a)

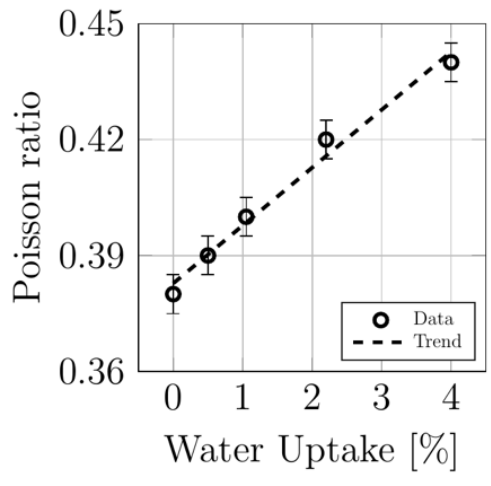

c)

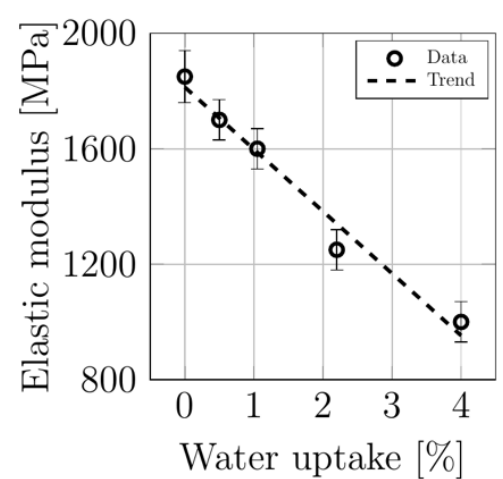

b)

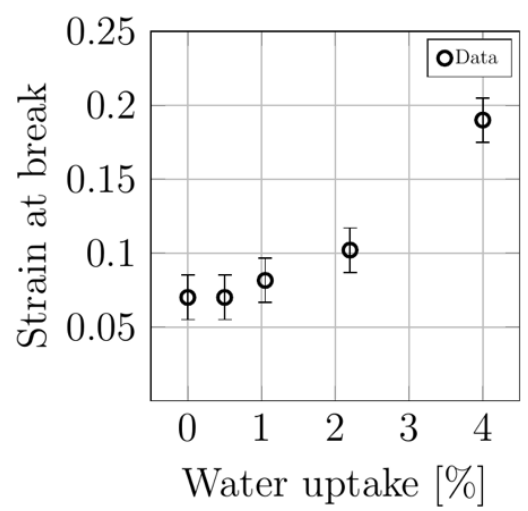

d)

Figure 5: Change in Yield stress (a), Young's modulus (b), Poisson's ratio (c), and Strain at break (d), as a function of water content in the polymer 
Figure 6 shows the $\mathrm{Tg}$ values as a function of water content in samples. A large decrease from $66^{\circ} \mathrm{C}$ in the dry state to $40^{\circ} \mathrm{C}$ after saturation in sea water (i.e. with $4 \%$ of water) is observed. The water solubility in polymers is not related to the state of the material meaning that the amount of water absorbed by a polymer (with no fillers) is not significantly affected when the polymer goes from the glassy to the rubbery state. This behaviour can be explained by the fact that the presence of water in the polymer leads to an increase of the macromolecular chains mobility and so a decrease in $\mathrm{Tg}$. This decrease in $\mathrm{Tg}$ with water content can be described by the Simha-Boyer equation [39]:

$$
\frac{1}{T_{g}}=\frac{1}{T_{g_{\text {polymer }}}}+A \times v_{\mathrm{H}_{2} \mathrm{O}} \quad \text { with } \quad A=\frac{1}{T_{g_{\mathrm{H}_{2} \mathrm{O}}}}-\frac{1}{T_{g_{\text {polymer }}}}
$$

where $\mathrm{Tg}$ is the predicted glass transition temperature, $T_{g_{\text {polymer }}}$ is the glass transition temperature of the polymer in the initial state, $T_{g_{H_{2} O} O}$ is the $\mathrm{Tg}$ of the solvent (here water), taken equal to $100 \mathrm{~K}$ (a value between the range of accepted values since the real $\mathrm{Tg}$ of water is difficult to measure [40]), and $v_{\mathrm{H}_{2} \mathrm{O}}$ is the volume fraction of water in the sample.

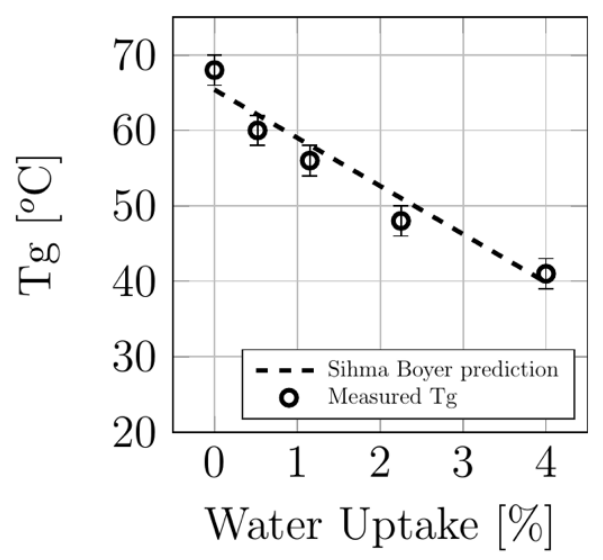

Figure 6: Decrease in Tg as a function of water content at saturation in the epoxy adhesive

\subsection{Tensile tests at different temperatures}

Since the presence of water increases the mobility in the polymer it leads to large changes in mechanical behaviour. An alternative way to increase mobility was then investigated, by increasing the testing temperature with dried samples. Tensile results are plotted in Figure 7. Large changes in the tensile behaviour are induced by an increase of the testing temperature up to $50^{\circ} \mathrm{C}$ (i.e. we are still in the glassy state). In fact, here again an increase of strain at break and Poisson's ratio are observed, as well as a decrease in the Young's modulus and the yield stress. All these properties are plotted in Figure 8. 


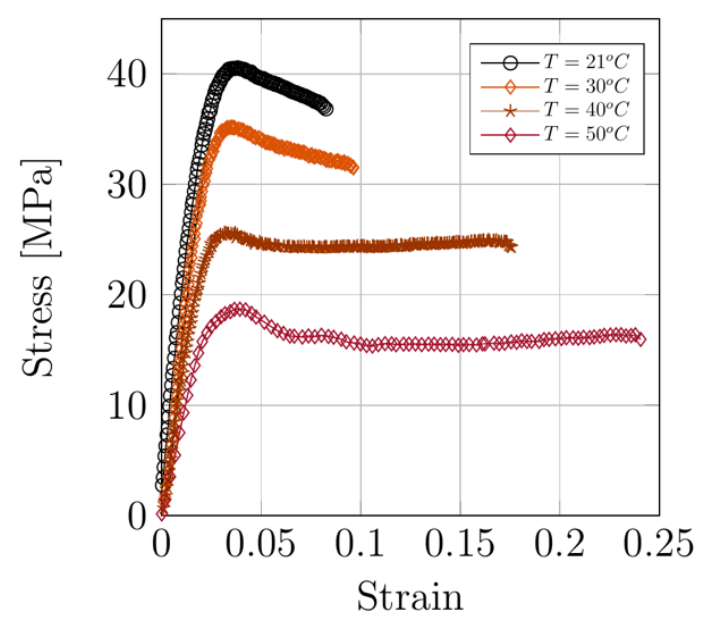

Figure 7: Tensile behaviour as a function of testing temperature on dry samples.

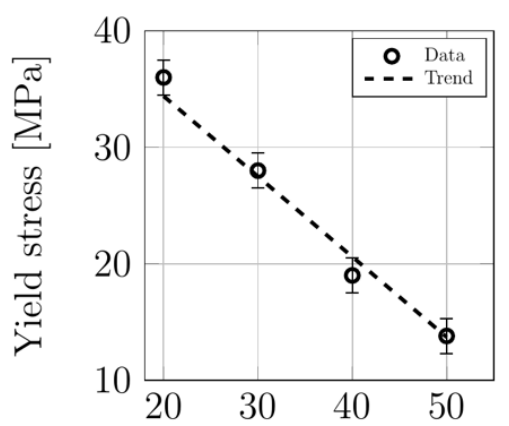

Testing temperature $\left[{ }^{\circ} \mathrm{C}\right]$

a)

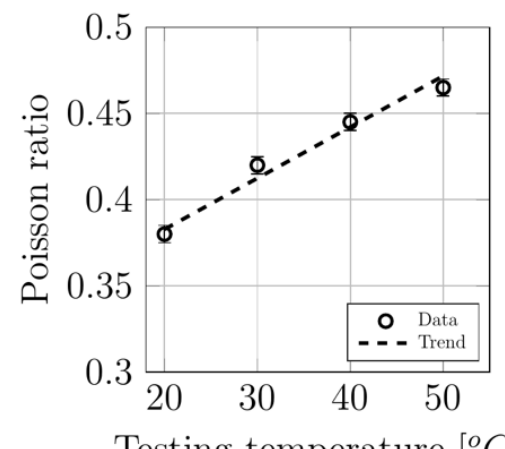

Testing temperature $\left[{ }^{\circ} \mathrm{C}\right]$

c)

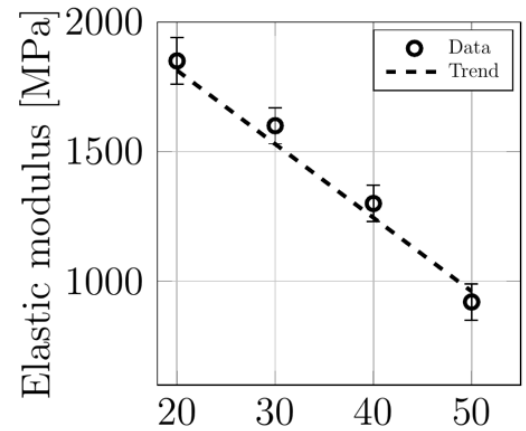

Testing temperature $\left[{ }^{\circ} \mathrm{C}\right]$

b)

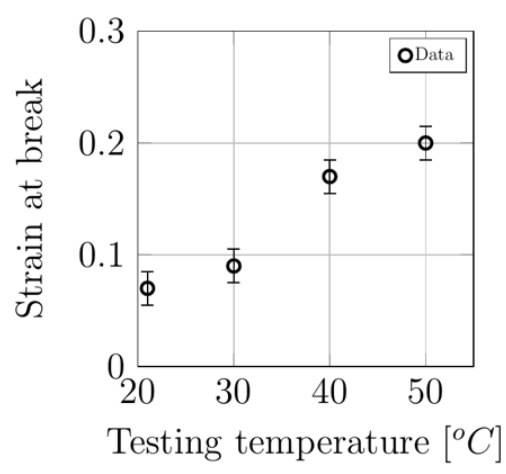

d)

Figure 8: Change in Yield stress (a), Young's modulus (b), Poisson's ratio (c), and Strain at break (d), as a function of testing temperature.

3.5 Tensile tests during ageing in sea water

The tensile behaviour of the bulk adhesive was also investigated after several immersion durations in sea water at $40^{\circ} \mathrm{C}$ before saturation of the sample, meaning that in this case there was a water profile gradient through the specimen thickness. A summary of the samples tested is presented in Table 2 and tensile behaviour is plotted in Figure 9. Here again the 
presence of water, even if there is a profile through the sample thickness, leads to a large decrease in modulus and yield stress. An increase of strain at break and Poisson's ratio is also observed; all these values are plotted as a function of immersion time in Figure 10.

\begin{tabular}{cc}
\hline $\begin{array}{c}\text { Ageing duration at } \mathbf{4 0}^{\circ} \mathrm{C} \text { in sea } \\
\text { water (hours) }\end{array}$ & $\begin{array}{c}\text { Amount of absorbed } \\
\text { water (\%) }\end{array}$ \\
\hline 6 & 1 \\
24 & 1.8 \\
55 & 2.8 \\
336 & 4
\end{tabular}

Table 2: Summary of ageing duration in sea water and corresponding amount of absorbed water

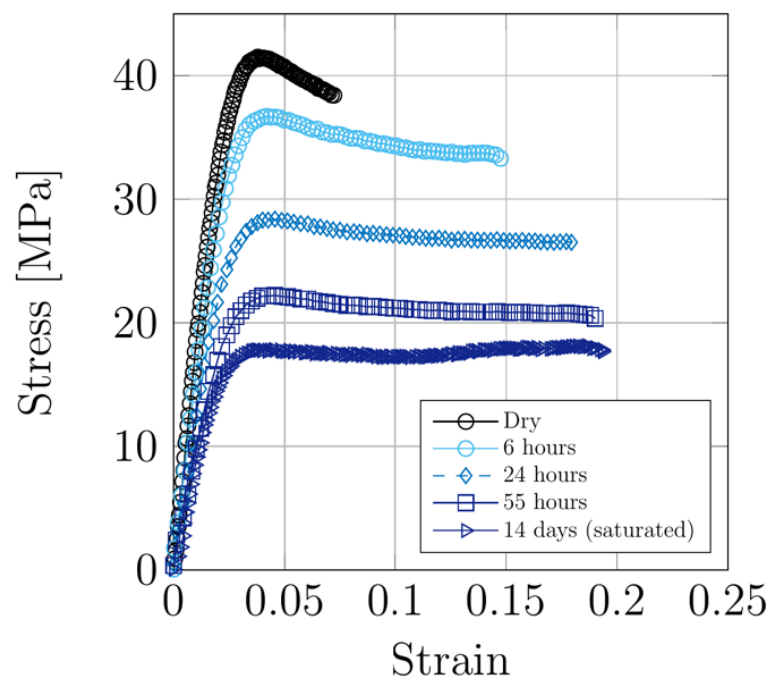

Figure 9: Tensile curves obtained for samples immersed in sea water at $40^{\circ} \mathrm{C}$ for several durations. 


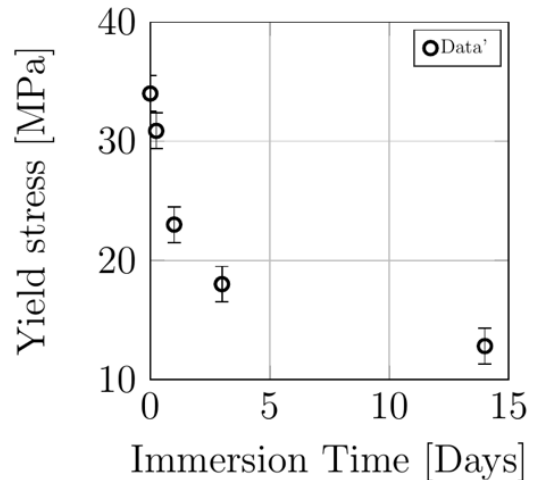

a)

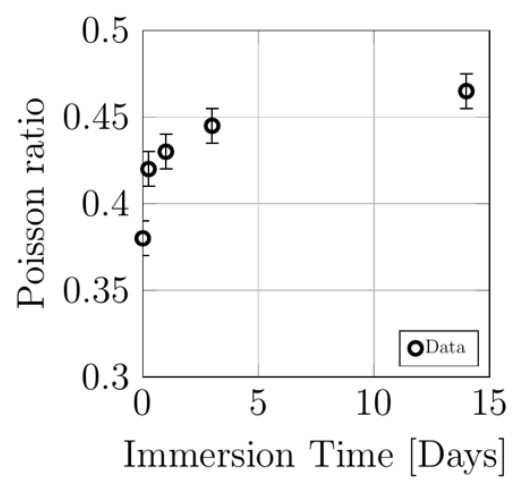

c)

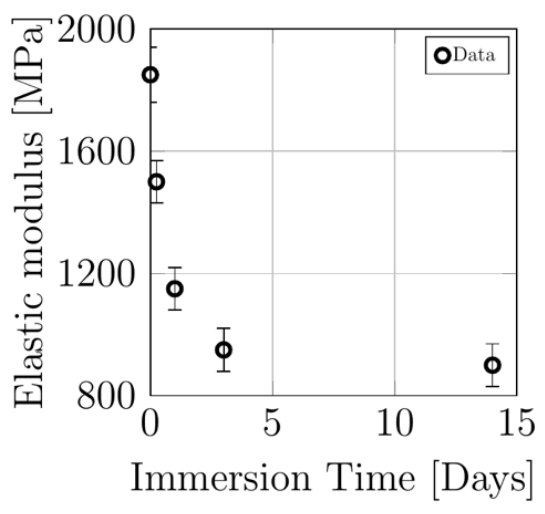

b)

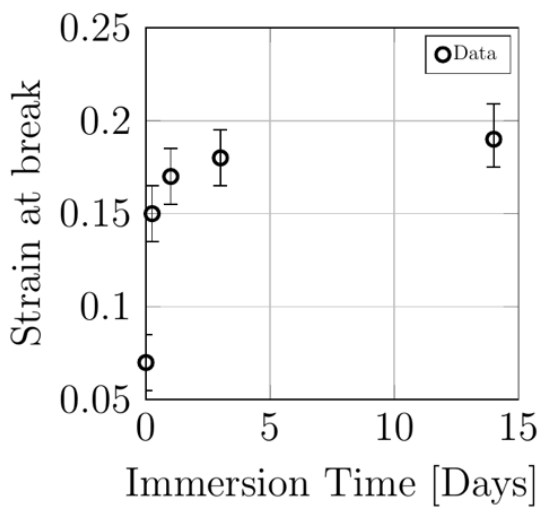

d)

Figure 10: Change in Yield stress (a), Young's modulus (b, and Poisson's ratio (c), Strain at break (d) as function of immersion time in sea water.

Furthermore, samples aged at $40^{\circ} \mathrm{C}$ for 14 days in sea water have then been dried in a desiccator at $40^{\circ} \mathrm{C}$ at less than $1 \% \mathrm{RH}$ to remove all the absorbed water. Tensile results before and after drying are plotted in Figure 11 and compared to those for unaged samples. A similar behaviour is observed, with the same modulus, yield stress and strain at break after drying, compared to unaged samples. It is interesting to note that there is a small strain softening effect after yield for unaged specimens; the reasons for this are not clear and further work is underway to examine the parameters which affect post-yield behaviour. 


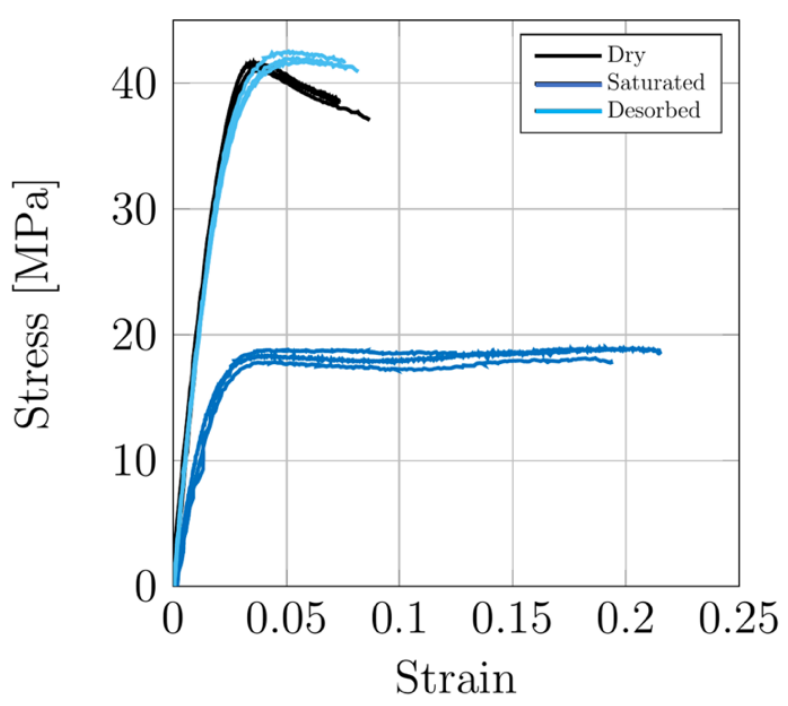

Figure 11: Tensile behaviour for unaged sample, fully saturated sample and sample dried after 14 days of ageing in sea water at $40^{\circ} \mathrm{C}$

\section{Discussion and prediction}

This section is devoted to the discussion of results presented previously with the aim to be able to predict the tensile behaviour of the epoxy studied here as a function of ageing.

\subsection{Degradation mechanism}

When exposed to humid environment, water diffuses into the polymer through a Fickian mechanism and the material absorbs up to $4 \%$ when immersed in sea water. The presence of water leads to an increase in mobility of the macromolecular chains and a decrease in $\mathrm{Tg}$ from $66^{\circ} \mathrm{C}$ to $41^{\circ} \mathrm{C}$, this phenomenon is well known as plasticization. Large changes in mechanical behaviour are induced by the plasticization: a decrease in stiffness as well as yield stress and an increase in strain at break and Poisson's ratio. The increase in the Poisson's ratio can be explained by the fact that the polymer tends towards its rubbery behaviour when $\mathrm{Tg}$ decreases. It is worth noting that the degradation observed here is fully reversible (Figure 11) meaning that plasticization is the only mechanism involved (for the ageing conditions used in this study).

\subsection{Prediction Set up}

A prediction of the mechanical behaviour of the bulk adhesive is now proposed using a multistep process. First, the water diffusion is modelled using a numerical FE approach. Second, the decrease in yield stress is described, based on physical considerations. Then changes in Young's' modulus are considered, and finally we will focus on the increase in Poisson's ratio with water content. 


\subsection{Prediction of water diffusion}

The prediction of water content through the thickness is the first step of the prediction and can be done using a typical Fickian behaviour coupled with the Eq.3. Water profiles are presented in Figure 12a for several immersion durations. Results obtained by modelling are then compared to experimental results in Figure $12 \mathrm{~b}$, and a good agreement is observed. This means that we are able to predict water content in the polymer as a function of thickness or external environment.
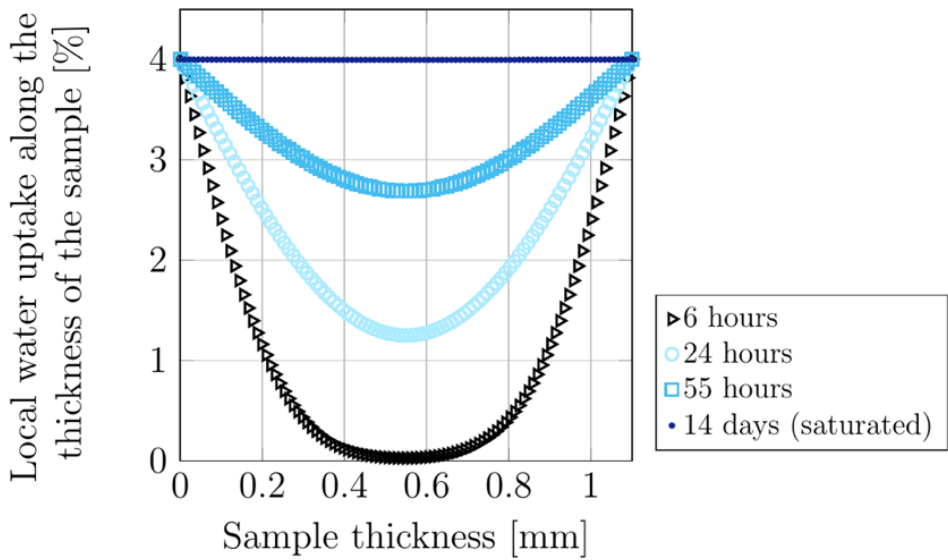

a)

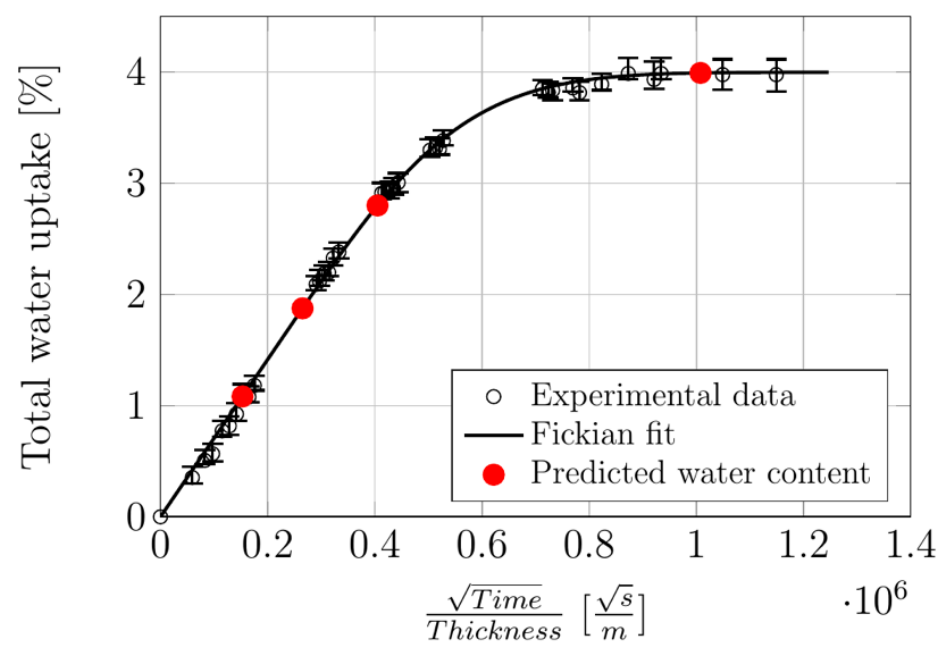

b)

Figure 12: Modelling of water diffusion when epoxy adhesive is immersed in sea water at $40^{\circ} \mathrm{C}$ a) water profile through thickness b) comparison between modelled water content (red dots) and experimental data (blue) 
Prediction of the yield stress is possible based on physical considerations. In fact, it has been shown that the yield stress is strongly affected by the mobility in polymer molecules and moreover is directly proportional to the difference between the polymer $\mathrm{Tg}$ and the testing temperature. This relationship can be expressed by the following Eyring relationship (Eq.7) that has been checked experimentally for several polymers [41][42][43]:

$$
\sigma_{y}=A \cdot\left(T_{g}-T\right)+B
$$

Here again, using both results on dry samples tested at different temperatures and samples saturated at several levels of water content (tested at $21^{\circ} \mathrm{C}$ ), it is possible to show that the Eyring relationship is verified here (Figure 13 ) with $A$ equal to 0.77 and $B$ equal to 0.2 . The correlation factor $\mathrm{R}^{2}$ is equal to 0.96 based on experimental results.

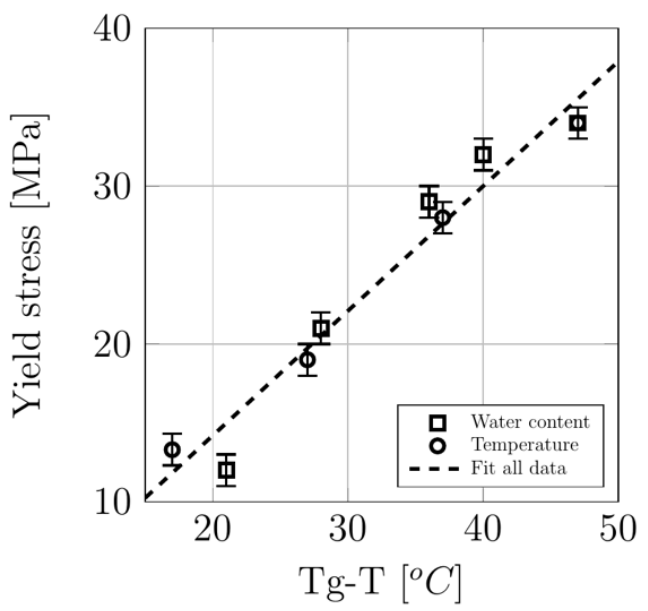

Figure 13: Relationship between yield stress and Tg-T obtained from tensile tests with several water contents at $21^{\circ} \mathrm{C}$, and at several testing temperatures on dry specimens.

Because we are able to model the water diffusion in the epoxy through the thickness and the $\mathrm{Tg}$ is related to water content through the Simha-Boyer equation it is possible to predict the local value of $\mathrm{Tg}$. Moreover, once the $\mathrm{Tg}$ is known it is possible to calculate the local value of Yield stress using the Eyring relationship.

\subsection{Description of Young's modulus decrease with water content}

The presence of water leads to a decrease in Young's modulus that can be explained by two main phenomena; the decrease in $\mathrm{Tg}$ and a decrease of the secondary transition. Unfortunately, due to the presence of these two mechanisms this behaviour cannot be described easily using physical considerations, thus an empirical relationship (Eq.8) was used to relate water content and the Young's' modulus value:

$$
E=1850-220 \times W_{H_{2} 0}
$$

where $E$ is the Young's modulus in $\mathrm{MPa}$ and $\mathrm{W}_{\mathrm{H} 20}$ is the water content in the polymer in \%.

This basic relationship is plotted in Figure $5 \mathrm{a}$ and compared to experimental results. It appears that despite its simplicity, it is useful to describe the Young's modulus loss. However, it is 
important to note that this relationship is only valid for a given test temperature, here $21^{\circ} \mathrm{C}$. It cannot be used to predict the evolution of properties at any other temperature.

\subsection{Description of Poisson's ratio changes with water content}

With the presence of water that leads to a decrease of $\mathrm{Tg}$, the polymer tends to move from glassy to rubbery behaviour. This leads to an increase of the Poisson's ratio that becomes closer to 0.5 , the value for a rubber. Here again this increase has been described using a linear empirical relationship:

$$
v=0.395+0.015 \times W_{H 20}
$$

Where $\mathrm{Nu}$ is the Poisson's ratio and $\mathrm{W}_{\mathrm{H} 20}$ is the water content in the polymer in \%.

Figure 5c shows that (Eq.9) can describe the increase in Poisson's ratio with water content at $21^{\circ} \mathrm{C}$, but again only for this temperature.

\subsection{Validation of the prediction}

Using the parameters identified in the previous section it appears that a prediction of the tensile behaviour at $21^{\circ} \mathrm{C}$ can be made during humid ageing: we are able to predict the water content through the thickness using a Fickian behaviour model. Knowing the local water content, it is then possible to define values for Young's modulus and Poisson's ratio using empirical equations 5 and 6 respectively. In parallel, it is possible to relate the water content to the $\mathrm{Tg}$ of the polymer and hence to define local yield stress using the physically-based relationship (section 4.4). The validity of this approach can now be considered by comparing experimental results obtained for different immersion durations in sea water (with water profile gradients) with predictions obtained by the model proposed here. The material models have been integrated in ABAQUS FE software (section 2.7) and the tensile specimen has been modelled. From the water profile the mechanical behaviour was calculated for increasing loads, and the resulting stress-strain behaviour was determined after different immersion times.

Results are plotted in Figure 14. A good agreement is observed between the predicted tensile behaviour and experimental data. 


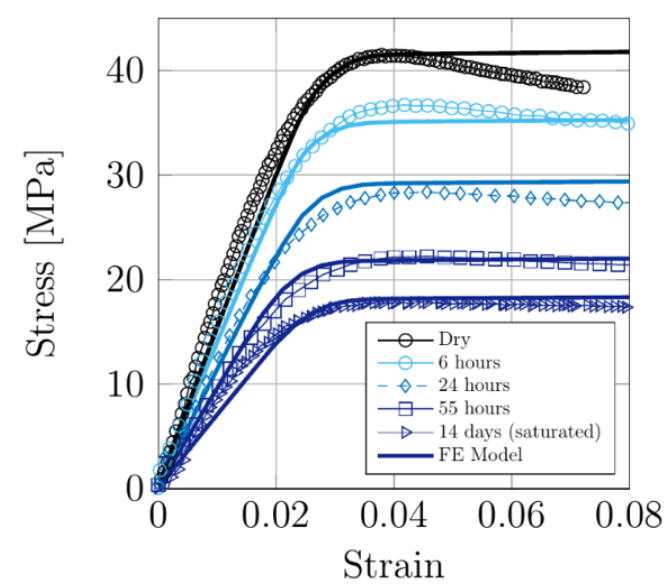

Figure 14: Comparison of predicted tensile behaviour (continuous lines) with experimental data (symbols) for different immersion times in sea water

\subsection{Limits of the prediction}

As for all predictions of mechanical changes during ageing, the one that is proposed here has some limitations. First, this prediction is limited to a mechanical behaviour at $21^{\circ} \mathrm{C}$ (testing temperature) because the temperature effect on Young's modulus and Poisson's ratio have not been considered here. Moreover, the model used here is not able to predict the strain at break, which is strongly affected by the presence of water. And finally, the relationships that have been identified in this study depend on the nature of the polymer, meaning that the approach developed here can be applied to other adhesives but it is not possible to use directly the values identified from this study.

\section{Conclusions}

This paper describes an approach to predict the influence of water on the tensile properties of an epoxy adhesive. It has been shown that for yield stress there is an equivalence between moisture content and test temperature, when these are expressed in terms of ( $\mathrm{T}-\mathrm{Tg})$, while Young's modulus and Poisson's ratio can be expressed as a function of moisture content. Using these relationships and an FE model to predict water profiles the influence of aging conditions on the tensile stress-strain behaviour has been predicted. Results are in good agreement with tests for specimens with different water profile gradients.

\section{Acknowledgements}

The authors are grateful to colleagues at the IFREMER Centre in Brest for their help with the aging measurements, in particular to Nicolas Lacotte and Mickael Premel Cabic. The work was performed within the French ANR COSICO project. 


\section{References}

[1]. Davies, P. Handbook of adhesion technology; Springer, 2011; pp 1237-1262

[2]. Silva, L.; Tognana, S.; Salgueiro, W. Polymer Testing 2013, 32, 158-164.

[3]. Toscano, A.; Pitarresi, G.; Scafidi, M.; Di Filippo, M.; Spadaro, G.; Alessi, S. Polymer Degradation and Stability 2016, 133, 255-263.

[4]. de Oliveira, G. L.; Gomez, A. J. A.; Caire, M.; Vaz, M. A.; da Costa, M. F. Polymer Testing 2017, 59, 290-295.

[5]. Zhou, J.; Lucas, J. P. Polymer 1999, 40, 5505-5512.

[6]. Zhou, J.; Lucas, J. P. Polymer 1999, 40, 5513-5522.

[7]. Brettle, J.; Brewis, D.; Comyn, J.; Cope, B.; Goosey, M.; Hurditch, R. International journal of adhesion and adhesives 1983, 3, 189-192.

[8]. De Nève, B.; Shanahan, M. International Journal of Adhesion and Adhesives 1992, 12, 191-196.

[9]. Mubashar, A.; Ashcroft, I. A.; Critchlow, G. W.; Crocombe, A. International Journal of Adhesion and Adhesives 2009, 29, 751-760.

[10]. Cowling, M. A Review of Adhesive Bonding for Offshore Structures; Health and Safety Executive, 1997.

[11]. Bordes, M.; Davies, P.; Cognard, J.-Y.; Sohier, L.; Sauvant-Moynot, V.; Galy, J. International journal of adhesion and adhesives 2009, 29, 595-608.

[12]. Brewis, D.; Comyn, J.; Tegg, J. International Journal of Adhesion and Adhesives 1980, 1, 35-39.

[13]. Zanni-Deffarges, M.; Shanahan, M. International Journal of Adhesion and Adhesives 1995, 15, 137-142.

[14]. Gledhill, R.; Kinloch, A.; Shaw, S. The journal of Adhesion 1980, 11, 3-15.

[15]. Liljedahl, C.; Crocombe, A.; Wahab, M.; Ashcroft, I. International Journal of Adhesion and Adhesives 2007, 27, 505-518.

[16]. Bowditch, M. International Journal of Adhesion and Adhesives 1996, 16, 73-79.

[17]. Comyn, J. Durability of structural adhesives; Applied science publishers, 1983; pp 85131.

[18]. Adams, R. D. Adhesive bonding: science, technology and applications; Elsevier, 2005.

[19]. Ashcroft, I. A.; Comyn, J. Handbook of adhesion technology; Springer, 2011; pp 787822.

[20]. Crocombe, A. International Journal of Adhesion and Adhesives 1997, 17, 229-238.

[21]. Wahab, M. A.; Crocombe, A.; Beevers, A.; Ebtehaj, K. International Journal of Adhesion and Adhesives 2002, 22, 61-73.

[22]. Crocombe, A.; Hua, Y.; Loh, W.; Wahab, M.; Ashcroft, I. International journal of Adhesion and Adhesives 2006, 26, 325-336.

[23]. Hua, Y.; Crocombe, A.; Wahab, M.; Ashcroft, I. International Journal of Adhesion and Adhesives 2008, 28, 302-313.

[24]. Katnam, K.; Sargent, J.; Crocombe, A.; Khoramishad, H.; Ashcroft, I. Engineering Fracture Mechanics 2010, 77, 3105-3119.

[25]. Arnaud, N.; Créac'hcadec, R.; Cognard, J.-Y.; Davies, P.; Le Gac, P.-Y. Journal of Adhesion Science and Technology 2015, 29, 2355-2380.

[26]. Mahnken, R.; Schlimmer, M. International journal for numerical methods in 
engineering 2005, 63, 1461-1477.

[27]. Leger, R.; Roy, A.; Grandidier, J. International Journal of Adhesion and Adhesives 2013, 44, 66-77.

[28]. Viana, G.; Costa, M.; Banea, M.; Da Silva, L. The Journal of Adhesion 2017, 93, 95112.

[29]. Viana, G.; Costa, M.; Banea, M.; da Silva, L. Proceedings of the Institution of Mechanical Engineers, Part L: Journal of Materials: Design and Applications 2017, 231, 488-501.

[30]. Le Gac, P.-Y.; Choqueuse, D.; Melot, D. Polymer Testing 2013, 32, 1588-1593.

[31]. ISO/TC 45/SC 2 Rubber, Vulcanized or Thermoplastic - Determination of Tensile Stress-strain Properties. 2011.

[32]. Badulescu, C.; Germain, C.; Cognard, J.-Y.; Carrere, N. Journal of Adhesion Science and Technology 2015, 29, 443-461.

[33]. Cognard, J.-Y.; Badulescu, C.; Maurice, J.; Créac'hcadec, R.; Carrère, N.; V edrine, P. International Journal of Adhesion and Adhesives 2013, 47, 46-56.

[34]. Park, G. S.; Crank, J. Diffusion in polymers; Academic Press, 1968.

[35]. Broudin, M.; Le Saux, V.; Le Gac, P.-Y.; Champy, C.; Robert, G.; Charrier, P.; Marco, Y. Polymer Testing 2015, 43, 10-20.

[36]. Gaudichet-Maurin, E.; Thominette, F.; Verdu, J. Journal of applied polymer science 2008, 109, 3279-3285.

[37]. Le Gac, P. Y.; Roux, G.; Davies, P.; Fayolle, B.; Verdu, J. Polymer 2014, 55, 2861-2866.

[38]. Fedors, R. Polymer 1980, 21, 207-212.

[39]. Kelley, F. N.; Bueche, F. Journal of Polymer Science Part A: Polymer Chemistry 1961, 50, 549-556.

[40]. Fayolle, B.; Verdu, J. Vieillissement physique des matériaux polymères; Tech. Ing.; 2005.

[41]. Kambour, R. Journal of Polymer Science: Macromolecular Reviews 1973, 7, 1-154.

[42]. Cook, W. D.; Mayr, A. E.; Edward, G. H. Polymer 1998, 39, 3725-3733.

[43]. Le Gac, P.-Y.; Arhant, M.; Le Gall, M.; Davies, P. Polymer Degradation and Stability 2017, 137, 272-280. 